\title{
What 'skeletal paleopathology' can teach us about arthritis. The contributions of the late Dr Juliet Rogers
}

\section{Quel che può insegnare la paleopatologia scheletrica in reumatologia. Il contributo degli ultimi studi di Juliet Rogers}

\author{
P. Dieppe ${ }^{1}$, L. Loe ${ }^{2}$, L. Shepstone ${ }^{3}$, I. Watt ${ }^{4}$ \\ ${ }^{1}$ Medical Research Council Health Services Research Collaboration, Department of Social Medicine, University of Bristol, UK; \\ ${ }^{2}$ Forensic and Bioarchaeological Sciences Group, School of Conservation Sciences, Bournemouth University, Poole, UK; \\ ${ }^{3}$ University of East Anglia, Norwich, UK; \\ ${ }^{4}$ Leiden University Medical Centre, The Netherlands
}

\section{INTRODUCTION}

Distan Juliet Rogers (Fig. 1), who died in 2001, aged 61 , devoted her working life to the study of ancient human skeletons to aid our understanding of disease - the science of 'skeletal paleopathology' $(1,2)$. She made many important contributions to rheumatology. Here we celebrate her work through a brief resume of some of the things her work has taught us about bone and joint disease.

\section{DIAGNOSING BONE AND JOINT DISEASE IN ANCIENT SKELETONS}

One of the most important contributions that Juliet Rogers made to our subject was to provide clear criteria for the diagnosis of bone and joint disease in skeletons. The field guide that she and Tony Waldron published in 1995 remains the definitive text on the subject (3). Based on their earlier work on inter-observer variations in coding osteoarthritis, the standards that Rogers and Waldron set out in this book now form the basis of national recommendations on the diagnosis of joint disease in dry bones (4).

If a skeleton from one of our ancestors is relatively well preserved, then it is possible for the pale-

\footnotetext{
Correspondence to:

Prof. Paul Dieppe

MRC HSRC, Canynge Hall, Whiteladies Road,

Bristol BS8 2PR, UK.

E-mail: p.dieppe@bristol.ac.uk
}

opathologist to examine all parts of the whole of the skeleton. They can look at the joint surfaces and joint margins of all joints from all angles. The can also obtain radiographs to compare what they see with what bony changes might be visualised using that diagnostic technique. The ability to examine everything in this way means that skeletal paleopathologists have a higher diagnostic 'sensitivity' to bone changes, a phenomenon that was illustrated in an elegant study comparing visual scoring of osteophytes in skeletons with what was seen on the

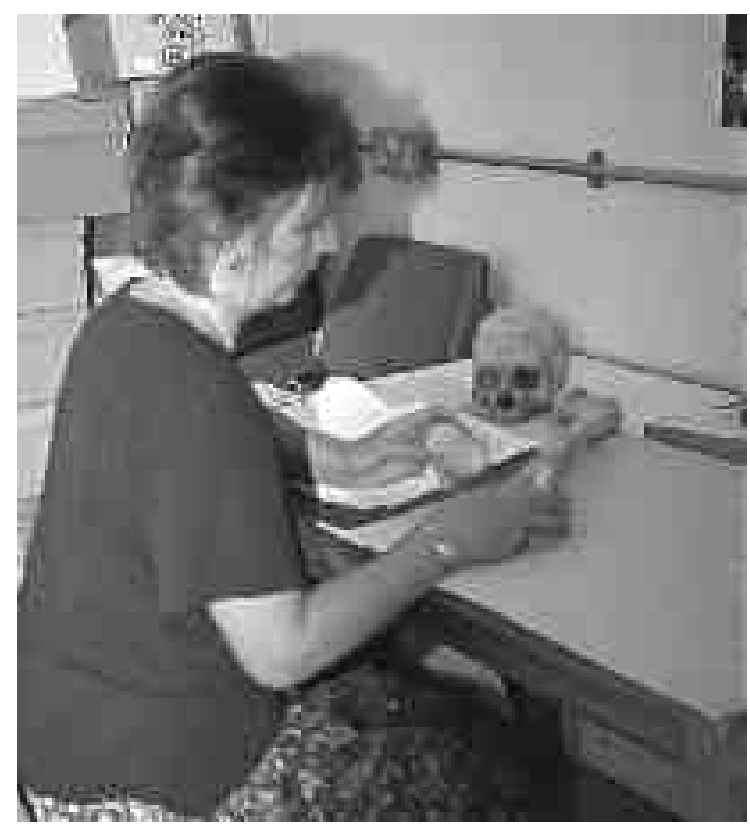

Figure 1 - Dr Juliet Rogers in her 'office' examining a skeleton. 


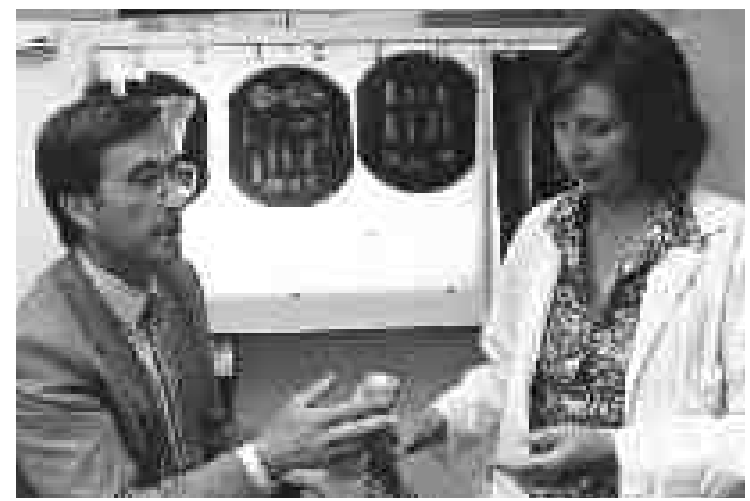

Figure 2 - Juliet Rogers and lain Watt discussing the findings on a human bone, and comparing the skeletal findings with those of the radiograph in an attempt to make an accurate diagnosis.

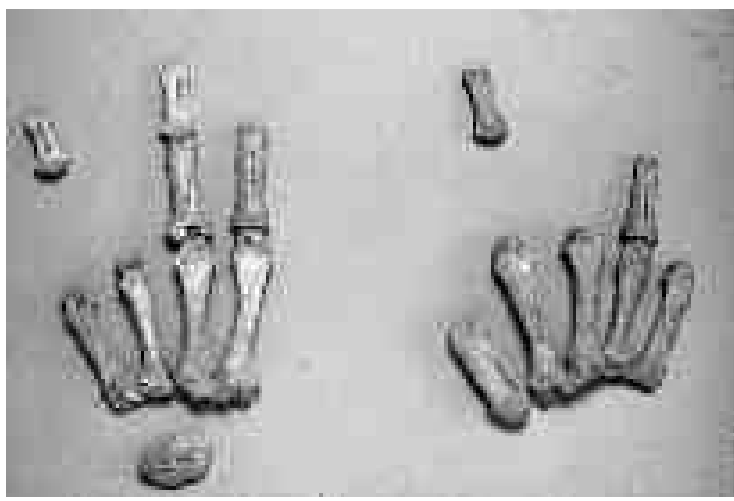

Figure 3 - The metacarpal bones and phalanges from a human skeleton, whose 'owner' may have had rheumatoid arthritis. Note the fact that many of the small bones are missing, making it harder to be sure of the pathology. Note also the erosions of the metacarpophalangeal joints. Close inspection showed that they were ante-mortum, as there was clear bone remodelling going on around them.

or historical perspective to the epidemiology of bone and joint disease (6).

There has been much debate about the antiquity of rheumatoid arthritis (RA), and whether or not environmental triggers to the disease include factors related to modern, urban life, such as air pollutants $(7,8)$. RA is one of the more difficult diagnoses to be certain of in a skeleton, but several probable examples have been well documented in the literature, some of them from Rogers and colleagues (911) (Fig. 3).

However, the numbers of cases of RA seen in the older collections is surprisingly small, particularly as there are many more clear cases of gout and sero-negative spondarthritis. This has led us, and others, to speculate that severe RA is a relatively 'new' disease, perhaps linked to urban living (11, 12). Alternatively it may be an 'epidemic' condition, that arose in the developed world some 2 or 300 years ago, and is now starting to disappear $(8$, 12, 13).

In contrast to RA, gout and some forms of seronegative spondylarthritis seem to have been prevalent in humans in many parts of the world for a very long time.

Juliet also showed that Paget's disease is an ancient condition, finding obvious examples of the condition in several ancient skeletons (14). This is important, because, as with the case of RA, there had been speculation that it might be associated with some infection or other environmental agent of relatively recent appearance, and be another passing 'epidemic'. 


\section{CHANGING PATTERNS OF RHEUMATIC DISEASE}

Rheumatoid arthritis may be a relatively recent disease. But is this because it has changed in expression, or because of the development of a new condition? We do not know. It could be that urban life leads to a change in the phenotype of the disease rather than much change in its prevalence; mild RA may have been present in many of our ancestors, but if there were a paucity of erosive changes, then we would not find it through the examination of ancient skeletons.

Skeletal paleopathology has taught us that some diseases do change over time. Osteoarthritis (OA) is a good example. In an important paper published in 1994, Rogers and Dieppe showed that the knee OA phenotype has changed, with the development of more tibiofemoral disease in recent centuries (15). OA of the hip and of the patellofemoral compartment of the knee joint are both seen frequently in skeletons of all ages from many parts of the world, but tibiofemoral OA only becomes common in skeletons from more recent burial sites (Tab. I). There are several possible explanations for this change in disease expression, the most obvious of which is that the development of more obesity and uptake of sports such as skiing and football that often lead to destabilisation of the tibiofemoral joint, may be responsible.

\section{THE INTER AND INTRA-JOINT DISTRIBUTION OF ARTHRITIS}

If one has access to a fairly complete skeleton (i.e. most of the bones of the same individual have been preserved in the burial site), then it is possible to examine the distribution of arthritis within and between joints. Juliet Rogers, in conjunction with Lee
Shepstone and others, put a lot of time into such analyses in order to try to understand patterns of distribution better, with an emphasis on OA.

They made many important discoveries. One of the most interesting findings, that has been presented at meetings and mentioned in a recent book chapter, but remains to be fully documented, is that OA of the elbow is a common finding in ancient skeletons. We rarely see elbow OA in our patients today. Is this because people do not have it, or because they do not complain about it? We favour the hypothesis that elbow OA is, and always has been, common, but that it rarely causes symptoms. If this were true, then we should perhaps turn our attention to the elbow joint in the search for improved understanding of pain generation in OA (16).

By having the opportunity to consider many joints of the body simultaneously, it is possible to consider the relationship between different joint sites. In a paper in which over 500 fairly complete skeletons were used for analysis (17), it was shown that $\mathrm{OA}$ in the lower limb (hip or knee) is associated with OA in the upper limb (hand, wrist, elbow and shoulder). This finding, together with elbow observation, lead the authors to postulate that the traditional conception of generalised OA (involving hands, hips and knees) should be considered as symptomatic generalised OA, distinct from pathological generalised $\mathrm{OA}$, which is not discernable in clinical studies.

Additional work has considered not only the pattern of OA involvement between joints but also patterns within joints. Considering osteophytes within the knee (18) it has been shown that a likely site of early osteophyte formation is within the intercondylar notch of the femur. It has also been shown that the shape of intercondylar notch varies between individuals with and without signs of OA (19). Whether this is due to bony remodelling in consequence of the OA process or preceeds the

Table I - Prevalence and ratios of hip and knee OA in Saxon/Mediaeval and Post-Mediaeval skeletons examined by Dr Rogers. Note the fact that a total of 29 skeletons had evidence of hip OA compared with 14 with patello-femoral joint (PFJ) knee OA, and only 4 with tibio-femoral knee joint (TFJ) OA (15).

\begin{tabular}{|llllll|}
\hline & \multicolumn{2}{ll}{ Saxon/Mediaeval } & \multicolumn{2}{l|}{ Post-Mediaeval } \\
\hline Hip OA & 26 & 3.7 & 3 & 3.3 & $\mathrm{p}=1.0$ \\
Knee OA & 13 & 1.8 & 5 & 5.5 & $\mathrm{p}=0.045$ \\
Ratio hip/knee & $2: 1$ & & $0.6: 1$ & & \\
\hline PFJ OA & 10 & 1.4 & 4 & 4 & \\
TFJ OA & 3 & 0.04 & 1.1 & \\
Ration PFJ/TFJ & $3.3: 1$ & & $4: 1$ & & \\
\hline
\end{tabular}


condition, and is a genuine risk factor, is yet to be determined.

Another intriguing finding is that ancient skeletons with OA often exhibit a pattern of arthritis that we might be tempted to call "chronic pyrophosphate arthropathy' in today's language, but in the absence of any evidence of chondrocalcinosis. In other words, they have prominent patello-femoral disease, involvement of the wrist and other sites less commonly involved in what we call 'primary OA', with florid osteophyte and enthesophyte formation (20). This we believe may be because that was part of the phenotype of OA in our ancestors, and not because they all had 'pyrophosphate arthropathy'. Indeed, in our view this finding adds weight to the argument that there is no such entity as pyrophosphate arthropathy (21).

Whether there is a different form of OA associated with chondrocalcinosis or not remains unclear. Similarly, we are still not sure whether 'generalised OA' exists as a clear separate entity, and if so, what its characteristics are (22). Skeletal paleopathology of the sort practiced by Juliet Rogers has the potential to sort these issues out for us.

\section{THE ASSOCIATION OF DIFFERENT TYPES OF PATHOLOGY WITHIN THE SAME SKELETON}

The ability of the paleopathologist to look at all aspects of the whole skeleton means that they have a major advantage over the clinician or radiologist when it comes to associating different types of pathology in the same skeletons. Diffuse idiopathic skeletal hyperostosis (DISH) is a not uncommon finding in ancients skeletons, particularly in people of higher socioeconomic status - for example, in local burial sites Juliet Rogers described a higher prevalence of DISH among individuals buried in church and chapel locations than among individuals buried in lay cemeteries (23, 34) (Fig. 4 and 5). In 1997 Rogers et al published a paper showing that the enthesophytes associated with DISH are associated with osteophyte formation (25). In this paper, the term 'bone former' was first used to define an individual, based upon the degree of osteophyte and enthesophyte formation, with a generalised propensity to form bone. The authors of this article went on to hypothesise that $\mathrm{OA}$ is a systemic disorder characterised by abnormal bone formation in response to stress on the bones and joints (17).
Another observation made by Juliet concerns a sample of Chumash Indian skeletons (1600 - 1800 $\mathrm{AD}$ ) that she examined whilst undertaking a study on the frequency and distribution of hip and knee OA in American skeletal populations. Despite being predominantly young, these individuals had a high prevalence of knee OA with lesions primarily located on the posterior parts of the condyles. Osteochondritis dissecans was also frequent among this group and similarly located. Habitual hyperflexion of the knees whilst kneeling or squatting was suggested as a possible explanation for the unusual location of these lesions (26)

Careful examination of the skeleton led to the recognition of other pathological features in association with OA, such as ridges, grooves and pitting on the articular surfaces. Grooving, the subject of one of Juliet's papers (27) is a phenomenon that is well known to the orthopaedic surgeons, who open up joints and see it in front of them, but is less well known to the rheumatologist or radiologist, neither of whom can see the phenomenon (Fig. 6). Similarly, the pitting of the articular surface is a

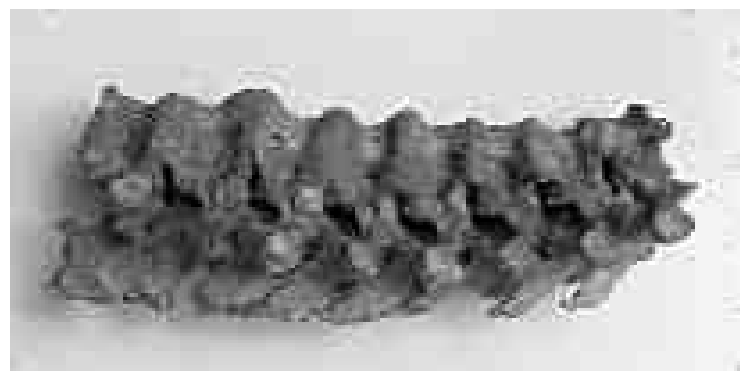

Figure 4 - The fused spine of an English Bishop, born some 850 years ago. The fusion is due to diffuse idiopathic skeletal hyperostosis (DISH) - one of the conditions that Juliet Rogers was most interested in.

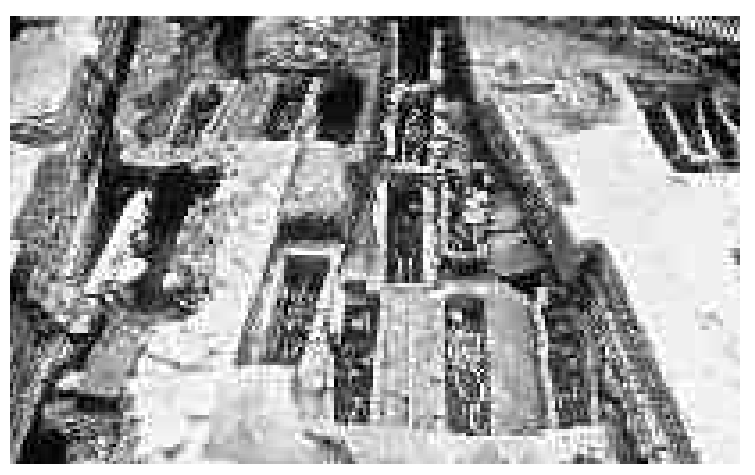

Figure 5 - The burial site of the clergy of Wells Cathedral, which was excavated some years ago, allowing Dr Rogers to examine the skeletons, amongst which she found several examples of DISH. 


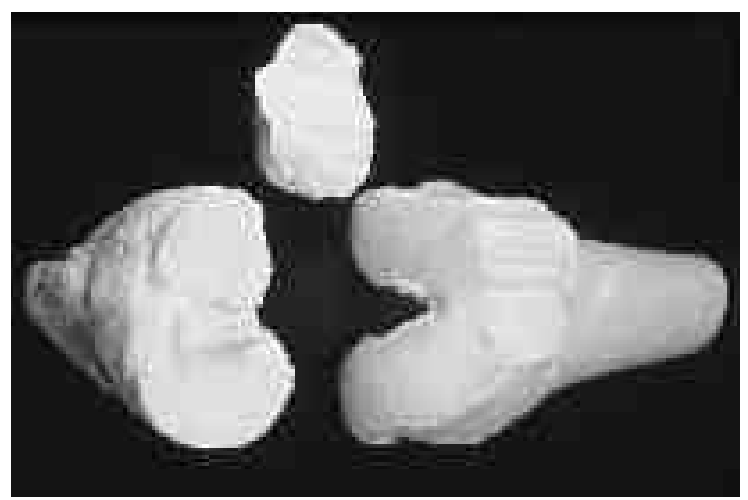

Figure $\mathbf{6}$ - A knee joint showing sclerosis of bone and grooving of bone in the patello-femoral joint. The bones have been specially treated to remove all remaining soft tissue and dirt, making them appear bleached. This was a technique introduced by Dr Rogers to make it easier to detect pathology in the skeletons she examined.

phenomenon barely discussed in the literature but a paper at a recent rheumatology meeting suggested that pitting is a common, though probably late occurring feature of OA (28). The other basic features of OA, osteophyte and sclerosis were looked at carefully in another Juliet inspired project. The assumption has been made that osteophyte and sclerosis parallel each other, are co-expressions of whatever $\mathrm{OA}$ is. Examining specimen femoral heads, some with marked osteophyte others with sclerosis, using DEXA and texture analysis showed that this was not true (29). An inverse relationship exists between osteophyte and sclerosis. Indeed, her work suggests that there may be two quite different processes in the OA joint, perhaps healing (osteophyte) and failure (sclerosis). There must be many more 'discoveries' of this sort waiting to be made by others who, like Juliet Rogers, are prepared to take time and care examining skeletons for signs of pathology.

\section{OTHER PRIMATES}

Humans are not the only animals to get arthritis, and they are not alone in sometimes bequeathing their skeletons for study by future generations. In the 1990s, with the help of Keith Lim, we compared hand OA in macaques and humans (30) and found that while distal interphalangeal joint disease was common in both species, thumb base OA was very rare in the macaques. This finding adds to the extensive evidence that joint utilisation is a major aetiological factor in OA, and supports the 'evolutionary hypothesis of OA' put forward by Charles Hutton (31). This led to other primate studies, and, in the late 1990s Juliet gained access to an extraordinary collection of non-human primate skeletons held at the Powell-Cotton Museum in England. She and Fiona Mair studied these skeletons, and showed that the distribution of their arthritis was clearly related to the type of joint utilisation (32).

\section{FUTURE DIRECTIONS}

The untimely early death of Juliet Rogers has left a void in the study of musculoskeletal diseases through skeletal paleopathology. There is still much to be done. The application of other technologies to study, for example, the shape of joints and bone densitometry in skeletons, was work that Juliet Rogers was just beginning to get into. Many more valuable insights will accrue if others can take this work forwards. However, her contributions, apparent in numerous publications that appeared over a 22 -year period $(26,33)$, were peerless.

\section{REFERENCES}

1. Ruffer MA. On Pathological lesions found in Coptic bodies (400-500 AD). J Pathol Bacteriol 1913; 18:149-62.

2. Ortner DJ. Identification of pathological conditions in human skeletal remains. Smithsonian Institute, Washington DC. 1981.

3. Rogers J, Waldron T. A Field Guide to Joint Disease in Archaeology. John Wiley and Sons. Chichester. 1995.

4. Roberts $\mathrm{C}$ and Connell B. Guidance on recording palaeopathology. In: M Brickley and JI McKinley (eds). Guidelines to the Standards for Recording Human Remains. Institute of Field Archaeologists and British Association for Biological Anthropology and Osteoarchaeology. University of Reading. 2004: 34-9.

5. Rogers J, Watt I, Dieppe P. Comparison of visual and radiographic detection of bony changes at the knee joint. BMJ 1990; 300:367-8

6. Dieppe P, Rogers J. Two-dimensional epidemiology. Br J Rheumatol 1985; 24: 310-2.

7. Domen RE. The antiquity and origins of rheumatoid arthritis JAMA 1992; 18: 2649.

8. Aceves-Avila FJ, Medina F, Fraga A. The antiquity of rheumatoid arthritis: a reappraisal. J Rheumatol 2001; 751-7.

9. Roberts C, Cox M. Health and Disease in Britain. From Prehistory to the Present Day. Sutton Publishing. Stroud. 2003.

10. Rogers J. 1988 Case histories. (Abstract). In: The An- 
tiquity of the Erosive Arthropathies. The Arthritis and Rheumatism Council for Research. Conference proceedings No. 5.

11. Rogers J. Palaeopathology. In: Graham AH and Davies SM. Excavations in Trowbridge, Wiltshire, 1977 and 1986-1988. The Prehistoric, Saxon and Saxo-Norman Settlements and the Anarchy Period Castle. Wessex Archaeology. Salisbury. 1993: 122-7.

12. Maddison P. (Editor). The antiquity of the erosive arthropathies. 1988. AARC Conference Proceedings, No 5. Arthritis Research Campaign, Chesterfield, UK.

13. Silman AJ. The changing face of rheumatoid arthritis: why the decline in incidence? Arthritis Rheum 2002; 46: 579-81.

14. Rogers J, Jeffery DR, Watt I. Paget's disease in an archaeological population. J Bone Miner Res 2002; 17: 1127-34.

15. Rogers J, Dieppe P. Is tibiofemoral osteoarthritis in the knee joint a new disease? Ann Rheum Dis 1994; 53: 612-13.

16. Dieppe P, Cushnaghan J, Rogers J, Shepstone L. The elbow: an important site of asymptomatic OA? Osteoarthritis Cartilage 2003; 11(Suppl A): S39

17. Rogers J, Shepstone L, Dieppe P. Is osteoarthritis a systemic disorder of bone? Arthritis Rheum 2004; 50: 452-7.

18. Shepstone L, Rogers J, Kirwan JR, Silverman B. The distribution of distal femoral osteophytes in a human skeletal population. Ann Rheum Dis 2000; 59: 513-20.

19. Shepstone L, Rogers J, Kirwan JR, Silverman B. A comparison between osteoarthritic and non-osteoarthritic femora with respect to the shape of the intercondylar notch. Ann Rheum Dis 2001;60:968-73

20. Steinbach LS, Resnick D. Calcium pyrophosphate dehydrate crystal deposition disease: imaging perspectives. Curr Probl Diagn Radiol 2000; 29: 209-29.
21. Dieppe P, Watt I. Crystal deposition in osteoarthritis: an opportunistic event? Clin Rheum Dis 1985; 11: 367-92.

22. MacGregor AJ. Genetics of osteoarthritis and osteoporosis. Reumatismo 2005; 57 (Numero Speciale 1): 30-2.

23. Rogers J. The skeletal remains. In: Rodwell W. Wells Cathedral. Excavations and Structural Studies, 1978-93. English Heritage. London. 2001: 546-62.

24. Rogers J, Waldron T. DISH and the monastic way of life. Int J Osteoarchaeol 2001; 11: 357-65

25. Rogers J, Shepstone L, Dieppe P. Bone formers: osteophyte and enthesophyte formation are positively associated. Ann Rheum Dis 1997; 56: 1-6.

26. Rogers J, Dieppe P. Paleopathology of osteoarthritis. In: Brandt K, Doherty M, Lohmander S. Osteoarthritis, 2nd Ed. Oxford, 2003: 59-65.

27. Rogers J, Dieppe P. Ridges and grooves on the bony surfaces of osteoarthritic joints. Osteoarthritis Cartilage 1993; 1: 167-70.

28. Shepstone L, Dieppe P. A Paleopathologic study of articular surface pitting Osteoarthritis Cartilage 2004; 12(Suppl B): S111

29. Sharma S, Rogers J, Watt I, Buckland-Wright C. Bone mineral density and fractal signature analysis in hip osteoarthritis. Clin Radiol 1997; 52: 872.

30. Lim K, Rogers J, Shepstone L, Dieppe P. The evolutionary origins of osteoarthritis: a comparative skeletal study of hand disease in two primates. J Rheumatol 1995; 22: 2132-4.

31. Hutton C. Generalised osteoarthritis, an evolutionary problem. Lancet 1987; 8548: 1463-5.

32. Mair F, Rogers J, Lim K, Dieppe P. Patterns of joint involvement in osteoarthritis. Support for the evolutionary hypothesis. Br J Rheumatol 1998; 37 (suppl. 1): 155.

33. Rogers J, Watt I, Dieppe P. Arthritis in Saxon and Mediaeval skeletons. BMJ 1981: 283: 1668-70. 